\title{
Robotic resection for esophageal cancer
}

\author{
Jan-Niclas Kersebaum (i) · Thorben Möller · Thomas Becker · Jan-Hendrik Egberts
}

Received: 19 March 2020 / Accepted: 1 September 2020 / Published online: 29 October 2020

(C) The Author(s) 2020

\begin{abstract}
Summary
Background In the surgical treatment of esophageal cancer, complete tumor resection is the most important factor and determines long-term survival. With an increase in robotic expertise in other fields of surgery, robotic-assisted minimally invasive esophagectomy (RAMIE) was born. Currently, there is a lack of convincing data on the extent of expected benefits (perioperative and oncologic outcomes and/or quality of life). Some evidence exists that patients' overall quality of life and physical function improves, with less fatigue and pain 3 months after surgery. We aimed to review the available literature regarding robotic esophagectomy, compare perioperative, oncologic, and quality of life outcomes with open and minimally invasive approaches, and give a brief overview of our standardized four-arm RAMIE technique and explore future directions.

Methods A Medline (PubMed) search was conducted including the following key words: esophagectomy, minimally invasive esophagectomy, robotic esophagectomy, Ivor Lewis and McKeown. We present the history, different techniques used, outcomes, and the standardization of robotic esophagectomy.

Results Robotic esophagectomy offers a steeper learning curve with fewer complications but comparable oncological results compared to conventional minimally invasive esophagectomy.

Conclusions Available studies suggest that RAMIE is associated with benefits regarding length of stay,
\end{abstract}

Dr. med. J.-N. Kersebaum • Dr. med. T. Möller ·

Prof. Dr. med. T. Becker · Prof. Dr. med. J.-H. Egberts $(\bowtie)$

Department of General, Visceral, Thoracic,

Transplantation and Pediatric Surgery, University Medical

Center Schleswig-Holstein (UKSH), Campus Kiel,

Arnold-Heller-Str. 3, 24105 Kiel, Germany

Jan-Hendrik.Egberts@uksh.de clinical outcomes, and quality of life-if patients are treated in an experienced center with a standardized technique for robotic esophagectomy-making it a potentially beneficial tool in the treatment of esophageal cancer. However, center-wide standardization and prospective data collection will be a necessity to prove superiority of robotic esophagectomy.

Keywords RAMIE - MIE - Learning curve · Standardization $\cdot$ da Vinci

\section{Introduction}

In the surgical treatment of esophageal cancer, complete tumor resection is the most important factor and determines long-term survival $[1,2]$. Unfortunately, less than $50 \%$ of patients initially present with local disease [3], which is suitable for resection [4]. Resection is associated with considerable morbidity and mortality, with complication rates ranging from $26-41 \%$ and perioperative mortality up to $10 \%$ when performed in a conventional open manner, but 5-year survival rates increase to up to $40 \%$ in patients who successfully undergo curative surgery [5]. The surgical approach depends upon many factors, with the most relevant being the location of the tumor, the tumor stage, and especially the surgeon's experience and preferences, and the institution's resources [6].

The pursuit of a reduction in perioperative mortality and morbidity in the treatment of esophageal cancer led to innovations in minimally invasive surgery, especially since the introduction of the da Vinci robotic system (Intuitive, Sunnyvale, CA, USA). With an increase in robotic expertise in other fields of surgery, RAMIE was introduce. Today, there is little convincing data on the extent of the expected benefits of RAMIE, including perioperative and oncologic outcomes and/or quality of life [4]. There is some 
evidence that that robotic approaches for esophagectomy improve patients' overall quality of life and physical function, and lead to less fatigue and pain 3 months after surgery [7]. Nonetheless, while RAMIE is a promising procedure, technical difficulties, long operating times, and lack of experience make this procedure difficult to adopt for many hospitals [8]. We aimed to review the available literature regarding RAMIE, compare perioperative, oncologic, and quality of life outcomes with open and minimally invasive approaches, give a brief overview of our standardized four-arm RAMIE technique, and explore future directions.

\section{Methods}

A Medline (PubMed) search was conducted on $24 \mathrm{Fe}-$ bruary 2020 including the following keywords: esophageal cancer, esophagectomy, open esophagectomy, minimally invasive esophagectomy, MIE, robot- assisted minimally invasive esophagectomy, RAMIE, robotic esophagectomy, lymph node dissection, and Ivor Lewis and McKeown. We reviewed all articles that were in the English language and discussed roboticassisted techniques. We also included an overview of our standardized approach and looked at future developments.

\section{Results}

The first robotic esophagectomy with an intrathoracic anastomosis was reported in 2002 by Melvin et al. [9]; the first totally robotic McKeown three-field esophagectomy was reported in 2004 by Kernstine et al. [10]. Since then, the number of publications regarding robotic esophagectomy per year has steadily increased. At first, published articles were merely case reports with small numbers of patients. Over time and with increasing experience, many authors began reporting their first results in robotic esophagectomy

Table 1 Publications reporting case reports or small case series concerning robotic esophagectomy

\begin{tabular}{|c|c|c|c|}
\hline Author & Period & Cases $(n)$ & Operation \\
\hline Melvin et al. [9] & 2002 & 1 & Hybrid robotic Ivor Lewis esophagectomy \\
\hline Giulianotti et al. [28] & 2000-2002 & 5 & Hybrid robotic McKeown esophagectomy \\
\hline Horgan et al. [29] & $\mathrm{NP}$ & 1 & Robotic transhiatal esophagectomy \\
\hline Kernstine et al. [10] & $2002-2003$ & 1 & Robotic Mckeown \\
\hline Bodner et al. [30] & 2002-2004 & 5 & Hybrid robotic Ivor Lewis esophagectomy \\
\hline Ruurda et al. [31] & 2000-2004 & 22 & Hybrid robotic Ivor Lewis esophagectomy \\
\hline Dapri et al. [32] & 2002 & 2 & Hybrid robotic McKeown esophagectomy \\
\hline Espat et al. [33] & NP & 15 & Robotic transhiatal esophagectomy \\
\hline Van Hillegersberg et al. [34] & 2003-2005 & 21 & Hybrid robotic Ivor Lewis esophagectomy \\
\hline Anderson et al. [35] & 2004-2007 & 25 & Hybrid robotic Ivor Lewis esophagectomy \\
\hline Kernstine et al. [36] & 2004 & 14 & Robotic Mckeown \\
\hline Braumann et al. [37] & 2002-2006 & 4 & Hybrid \\
\hline Galvani et al. [38] & 2001-2004 & 18 & Robotic transhiatal esophagectomy \\
\hline Boone et al. [39] & 2003-2007 & 47 & Hybrid robotic Ivor Lewis esophagectomy \\
\hline Kim et al. [40] & $2006-2008$ & 21 & Hybrid robotic McKeown esophagectomy \\
\hline Puntambekar et al. [41] & NP & 32 & Hybrid robotic Ivor Lewis esophagectomy \\
\hline Dunn et al. [42] & $2007-2010$ & 40 & Robotic transhiatal esophagectomy \\
\hline Suda et al. [43] & 2009-2011 & 16 & Hybrid robotic McKeown esophagectomy \\
\hline Cerfolio et al. [44] & 2012 & 22 & Hybrid robotic Ivor Lewis esophagectomy \\
\hline De la Fuente et al. [45] & 2010-2011 & 50 & Hybrid robotic Ivor Lewis esophagectomy \\
\hline Diez Del Val et al. [46] & 2009-2012 & 16 & All \\
\hline Hernandez et al. [47] & 2010-2011 & 52 & Robotic Ivor Lewis esophagectomy \\
\hline Ishikawa et al. [48] & 2010-2011 & 4 & Hybrid robotic McKeown esophagectomy \\
\hline Mori et al. [49] & NP & 1 & Robotic transhiatal esophagectomy \\
\hline Weksler et al. [50] & 2008-2009 & 11 & Hybrid robotic McKeown esophagectomy \\
\hline Sarkaria et al. [51] & NP & 21 & Robotic Ivor Lewis esophagectomy/robotic Mckeown \\
\hline Coker et al. [52] & 2006-2012 & 23 & Robotic transhiatal esophagectomy \\
\hline Sarkaria et al. [53] & 2012-2013 & 42 & Robotic Ivor Lewis esophagectomy/robotic Mckeown \\
\hline Trugeda et al. [54] & 2008-2013 & 18 & Hybrid robotic Ivor Lewis esophagectomy \\
\hline Puntambekar et al. [55] & 2009-2012 & 83 & Hybrid robotic McKeown esophagectomy \\
\hline Egberts et al. [22] & 2013-2017 & 75 & Robotic Ivor Lewis esophagectomy \\
\hline
\end{tabular}


in small case series. In a recent review, Murthy et al. [11] described early to fairly recently reported robotic esophagectomy series, including the number of cases and the operation (Table 1). Some surgical outcome parameters were also reported within these relatively small cohorts, where the leakage rate ranged from $0-40 \%$ and the length of hospital stay from 7-21 days.

\section{Different RAMIE techniques}

Currently, there are three main techniques in use: (1) totally robotic transhiatal esophagectomy (THE) with thoracic anastomosis; (2) totally robotic Ivor Lewis (IL) esophagectomy with a thoracic anastomosis; (3) totally robotic three-field McKeown esophagectomy with a cervical anastomosis. Other reported techniques consist of various hybrid combinations of the abdominal and thoracic phase of the operation being performed, using video-assisted thoracoscopic surgery (VATS)/minithoracotomy/thoracotomy and laparoscopy/minilaparotomy/hand port or full laparotomy. A general overview over the different techniques is shown in Fig. 1. In addition, there is no consensus regarding the ideal anastomotic technique for the esophagogastric anastomosis.

There are various options available for the cervical anastomosis, consisting of a two-layer handsewn, circular-stapled or linear-stapled technique (modified collar) fashioned in an end-to-end, end-to-side, or side-to-side fashion. For the intrathoracic esophagogastric anastomosis, which is used in during robotic IL esophagectomy, there is another option: the OrVil (Medtronic, Meerbusch, Germany) transoral circular stapling device, which permits transoral placement of the anvil. A paper from Kang et al. [12] described their preliminary experience in a case series with 215 patients undergoing minimally invasive IL esophagectomy, which they found to be feasible and safe to use, with an anastomotic leakage rate of only $2.7 \%$. These big differences in approach, anastomotic location, and technique arose from the fairly limited experiences in the early days of the robotic esophagectomy.

To determine the value of the robotic approach in the treatment of esophageal cancer, we compared it to standard therapies.

\section{Oncological and operative outcomes}

Tagkalos et al. [13] compared the results of 50 robotic IL esophagectomy procedures with 50 conventional MIE operations performed by the same surgeon, using an identical intrathoracic anastomotic reconstruction technique with the same perioperative management and pain control regimen. They found a higher lymph node yield in the robotic group compared to the MIE group ( 27 vs. 23 , respectively; $p=0.053$ ) with no statistically significant differences. However, there was a significantly lower median intensive care stay after RAMIE (1 days vs. 2 days). The incidence of postoperative complications was not significantly different between the two groups. The leakage rate was higher in the MIE group than the RAMIE group (18\% vs $12 \%$ ), but with no statistically significant difference.

Zhang et al. [14] recently compared MIE to RAMIE in 66 matched pairs, also using propensity score-matched cohorts. They found that the mean ( \pm standard deviation) operative time was significantly longer with RAMIE than the thoracoscopic-assisted IL (TAIL) group $(302.0 \pm 62.9$ vs. $274.7 \pm 38.0 \mathrm{~min}$, $P=0.004)$. There was no significant difference in the rates of overall complications $(28.8 \%$ vs. $24.2 \%$ for RAMIE vs. TAIL, respectively), or in the median (interquartile range) blood loss (200.0 $\mathrm{ml}$ [100.0-262.5] vs. $200.0 \mathrm{ml}$ [150.0-245.0]), length of stay (9.0 [8.0-12.3] days vs. 9.0 [8.0-11.3] days), and total mean ( \pm standard
Fig. 1 Different techniques for minimally invasive esophagectomy

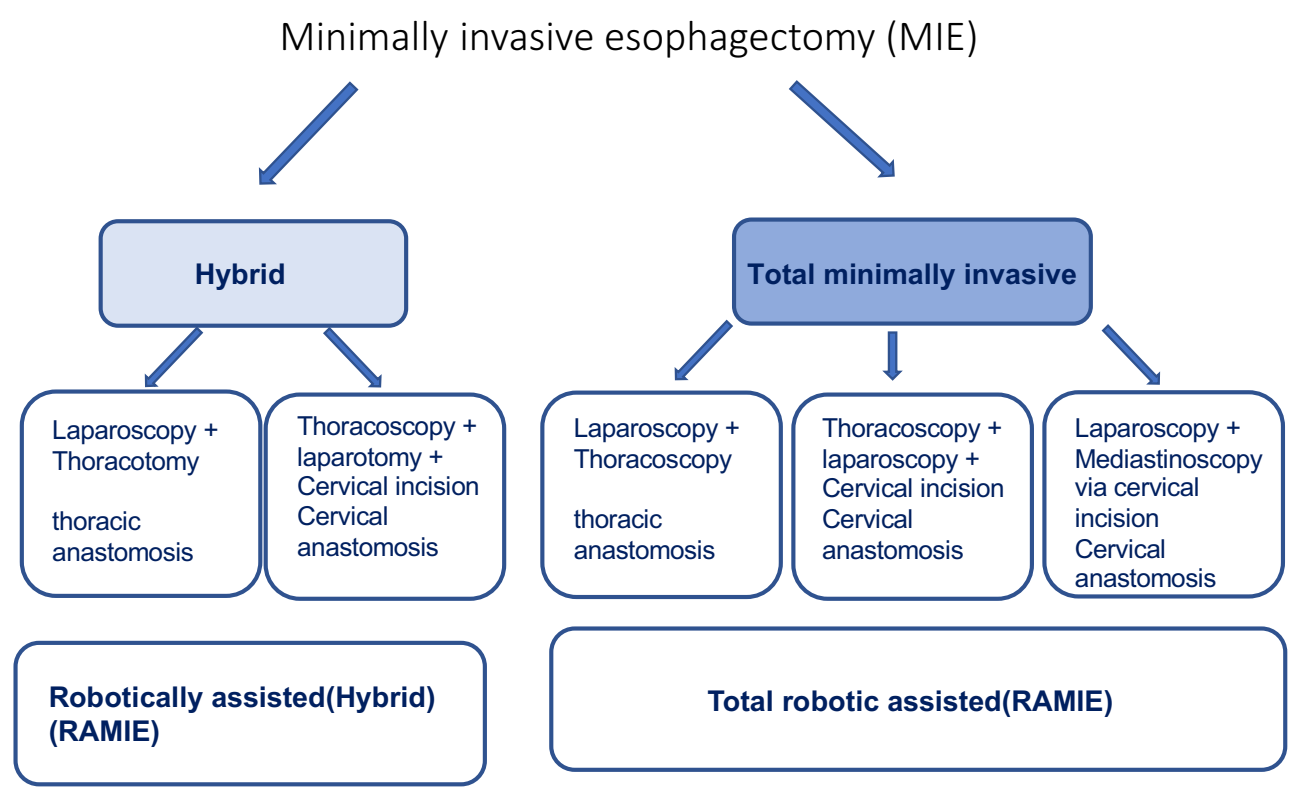




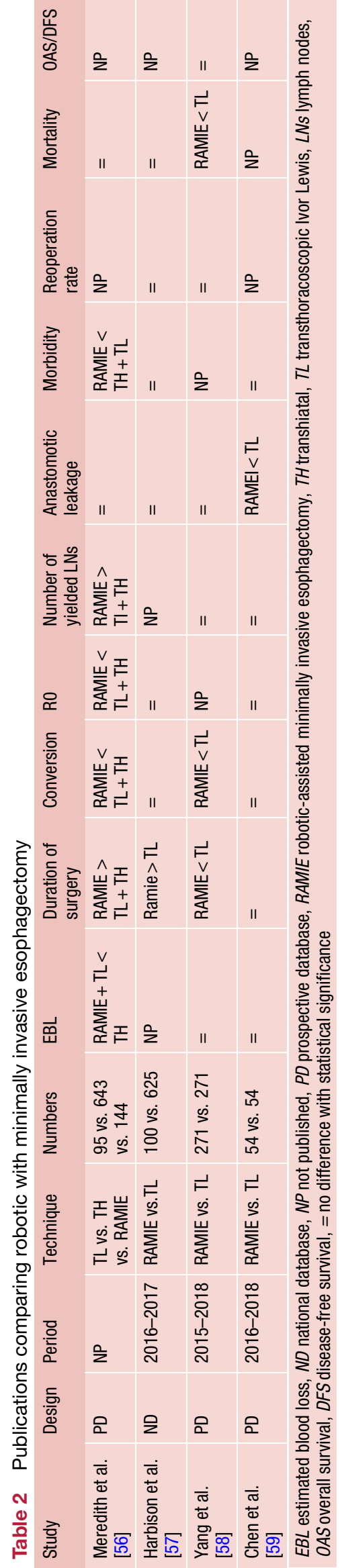

deviation) number of dissected lymph nodes $(19.2 \pm 9.2$ vs. 19.3 $\pm 9.5, P=0.955$ ). There were two conversions in the RAMIE group, and there were no 30-day readmissions.

Other studies comparing outcomes are shown in Table 2. In 2018 our colleagues Grimminger et al. [15] compared the outcome of RAMIE, MIE, and hybrid esophagectomy (laparoscopic abdominal and open thoracic phase). It has to be noted that the hybrid esophagectomy is the most common performed technique today. They found no statistically difference between those three groups regarding total hospital stay, intensive care unit stay, lymph node yield or R status. There were significantly fewer cases of pneumonia or surgical side infections in the minimally invasive groups (MIE + RAMIE) compared to the hybrid approach. It is noteworthy that all of those studies show a noninferiority of the robotic approach in comparison to the open or even the minimally invasive esophagectomy.

The only available prospective randomized trial comparing RAMIE and open transthoracic esophagectomy (OTE) ("ROBOT-Trial") was performed by van der Sluis et al. [16]. Results showed that RAMIE resulted in a lower percentage of overall surgery-related and cardiopulmonary complications, with lower postoperative pain, better short-term quality of life, and better short-term postoperative functional recovery compared to OTE, and comparable oncological outcomes in concordance with the highest standard. The rate of anastomotic leakage was higher with RAMIE (24\%) than OTE (20\%), but without reaching statistical significance. This was widely discussed and was narrowed down to the impact of the learning curve on the surgical outcome. These high rates of anastomotic leakages could also explain the high rate of inhospital and 90-day mortality, being both higher in the RAMIE ( $4 \%$ and $9 \%$, respectively) than OTE group ( $2 \%$ and $2 \%$, respectively). Again, this did not reach statistical significance.

Whether RAMIE is superior to conventional MIE, which has also shown comparable benefits compared to OTE in a randomized controlled trial [17], has yet to be proven. We are awaiting the results of the first multicenter prospective randomized controlled trial comparing RAMIE with MIE. The follow-up will terminate 5 years after the last enrollment, and the first results are expected to be published in 2022 [18].

\section{Costs}

The costs of running a robotic program can be divided into two categories: the fixed and variable costs. The fixed costs include the purchase costs of the system and the costs for maintenance. The variable costs include the costs for the instruments and covers and also cost of using the operation room. With a longer total operating time using the robotic systems, this makes the RAMIE more expensive compared to MIE 
or open esophagectomy. However, if the down-time of the robotic systems is decreased through an adequate interdisciplinary usage, the overall operating time is reduced with a gain in experience, the cost per instrument is reduced though batch purchases, and secondary costs become lower with a lower rate off postoperative complications, and the overall extra costs might decrease. However, there still is not sufficient data about whether the secondary cost saving counterbalance the primary investment.

\section{Standardization of RAMIE}

The implementation of robot-assisted surgery requires a multidisciplinary approach, with appropriate training and cooperation of surgical, anesthetic, and technical staff. Besides acquiring the technical skills and becoming used to the complex technique, patient selection and an appropriate frequency of procedures are required to avoid complications [19].

Analogous to the proctoring program in the implementation phase of radical prostatectomy [20], our colleagues from UMC Utrecht developed a structured training program to guide an upcoming RAMIE surgeon through the learning curve [21]. It consists of three case observations in a specialized RAMIE center, followed by a basic course in robot handling and training on human cadavers. The experienced proctor then supports the trainee in their first 3-10 esophageal resections.

Following implementation, standardization takes place. This allows continuous re-evaluation of the technique to identify recurring technical and/or procedural problems. To facilitate this process, so-called procedure guides can be helpful. In 2017, Egberts et al. [22] published a standardized technique for the robotic four-arm IL esophagectomy. After many alterations, we present our standardized technique for RAMIE. Initially, handsewn anastomosis were performed; however, after internal re-evaluation of outcomes, we switched to a circular-stapled anastomosis. Our established technique is described below.

\section{Patient setup for the abdominal phase}

With the arms set parallel to the torso, the patient is positioned in a reverse Trendelenburg position at a $25^{\circ}$ angle with a $10^{\circ}$ rotation to the right. After port placement, the robotic side cart is docked, and the surgical assistant is positioned on the righthand side of the patient.

\section{Surgical steps of the abdominal phase}

After dissection of the hepatic artery and the lymph node dissection up to the celiac axis, the branches of the splenic and left gastric artery are prepared. The gastric mobilization is done in a medial to lateral approach. After dissecting and widening the hiatus, the esophagus can be released circumferentially and mobilized high into the mediastinal cavity. The stomach is then mobilized tension-free from the pylorus up to the level of the right crus of the diaphragm.

A gastric tube with an approximately $5-\mathrm{cm}$ diameter is created, starting from the antrum of the greater curvature, and carefully elongated with the robotic instruments. With a linear stapler, the conduit is partially formed. This allows length adjustment during the thoracic phase. The abdominal phase is concluded with the implantation of a feeding probe in the first jejunal loop [22]. Table 3 shows the instruments used in the abdominal phase.

\section{Patient setup for the thoracic phase}

After being repositioned to a left lateral decubitus position, a further ventral rotation is necessary to reach a modified prone position, to allow quick conversion to open surgery if necessary. Our instruments used during the thoracic phase are shown in Table 4.

\section{Surgical steps of the thoracic phase}

After initiating a single lung ventilation, the thoracic ports are placed and the robotic cart is docked. The azygos vein is dissected along its full intrathoracic length and divided between two large clips; the aortic adventitia, the mediastinal pleura, and the pericardium are dissected along anatomical planes for en bloc resection of the esophagus and parae-

Table 3 Instruments used in the abdominal phase

\begin{tabular}{|c|c|c|c|c|}
\hline Step of operation & Arm 1 & Arm 2 & Arm 3 & Arm 4 \\
\hline $\begin{array}{l}\text { Lymphadenectomy and gastric and } \\
\text { esophageal mobilization }\end{array}$ & $\begin{array}{l}\text { Fenestrated bipolar } \\
\text { forceps }\end{array}$ & $30^{\circ}$ camera & $\begin{array}{l}\text { Monopolar curved scissors, Harmonic ACE }{ }^{\circledR} \text { Curved } \\
\text { Shears }{ }^{\mathrm{a}} \text {, Vessel Sealer }\end{array}$ & $\begin{array}{l}\text { Tip-up fenestrated } \\
\text { grasper }\end{array}$ \\
\hline Gastric tube creation & $\begin{array}{l}\text { Fenestrated bipolar } \\
\text { forceps }\end{array}$ & $30^{\circ}$ camera & Harmonic ACE ${ }^{\circledR}$ Curved Shears ${ }^{\mathrm{a}}$ & $\begin{array}{l}\text { Tip-up fenestrated } \\
\text { grasper }\end{array}$ \\
\hline Implantation of feeding probe & $\begin{array}{l}\text { Fenestrated bipolar } \\
\text { forceps }\end{array}$ & $30^{\circ}$ camera & Large needle driver & $\begin{array}{l}\text { Tip-up fenestrated } \\
\text { grasper }\end{array}$ \\
\hline
\end{tabular}

Table 4 Instruments used during the thoracic phase

\begin{tabular}{|l|l|l|l|l|}
\hline Step of operation & Arm 1 & Arm 2 Arm 3 & Arm 3 & Armopolar curved scissors \\
\hline Thoracic esophageal dissection & Tip-up fenestrated grasper & Fenestrated bipolar forceps & $30^{\circ}$ camera & Monom \\
\hline Fashioning the anastomosis & Fenestrated bipolar forceps & - & $30^{\circ}$ camera & Large needle driver \\
\hline
\end{tabular}


sophageal tissue. The gastric tube is mobilized into the thoracic cavity. Afterwards, the specimen can be removed, and the length and perfusion of the gastric tube is examined. An end-to-side esophagogastrostomy using a circular stapler is then done and finished with a circular stitch over. Finally, the trocar wounds are closed and a chest tube is placed.

After improving our technique to the actual state, we used the so-called double console to enable inexperienced surgeons to gain initial experience by taking over part of the operation. The experienced surgeon at the second console always has the possibility of taking control of the robot with little effort. In this way, even complex substeps can be learned step-by-step without increasing the risk for the patient.

\section{Improved teaching methods in standardized RAMIE}

Van Worksum et al. [23] analyzed the data of 646 patients who underwent conventional MIE. Using the CUSUM analysis, they found that in 119 cases the length of learning curve was based on anastomotic leakage. During the learning curve, the incidence of leakage decreased from a mean of $18.8 \%$ to $4.5 \%$ after the 119 cases. Using the area under the curve method, they concluded that in 36 patients $(10.1 \%)$ the anastomotic leakage was associated with the learning curve, drastically increasing the mortality, which could have been prevented if these patients had been operated by a surgeon who had already completed the learning curve. In comparison, van der Sluis et al. [24] reported the RAMIE learning curve to be much lower. They found that 70 procedures over 55 months were necessary to reach a plateau. If proctored by an experienced surgeon, the learning curve steepened. They were able to show a $76 \%$ reduction in the time needed to finish the learning curve (to just 13 months), and a $66 \%$ reduction in the number of operations needed (24 cases). This makes RAMIE more feasible for surgeons in smaller hospitals.

After successful implementation, it is vital to regularly monitor the approach used and adapt it based on results. However, there is still no definitive data regarding the best way for fashioning the anastomosis. A review from Plat et al. [25] analyzed the different anastomotic approaches and stated that with limited robotic experience, circular stapling might be the preferred technique; however, this requires a well-trained bedside assistant. The linear-stapling technique or handsewn technique are more challenging but enable experienced robotic surgeons to perform a controlled anastomosis without bedside support.

\section{Outlook}

In the quest towards reducing the intraoperative risk for patients while reaching for the best oncological outcome possible, many experts worldwide have tried to expand the boundaries. In 2019, Egberts et al. [26] published a case series of a new robotic approach called robotic-assisted cervical esophagectomy (RACE), which uses a single port combined with a transhiatal approach in a rendezvous technique. For the proof of concept, they first tried the individual surgical steps using cadavers in a medical training center (Medizin im Grünen, Wendisch Rietz, Germany), then refined them with increasing experience. This procedure should reduce the risk of pulmonary complications because no single lung ventilation or thoracic access are necessary. In all cases, RACE was completed by a cervical robotic approach and a laparoscopic transhiatal dissection. No conversion to conventional robotic-assisted transthoracic esophagectomy or open surgery was needed. The mean (range) operating time was 344 (292-433) min, with a blood loss of $120(20-180) \mathrm{ml}$. All patients underwent curative surgery with pathologically negative circumferential resection margins. Overall, this method could be applied to patients who otherwise may not be suitable for surgical therapy due to other comorbidities.

Particularly against the background of the planned market launch of the da Vinci Single Port System, the rapid development in this field of surgery is certainly not yet complete. In addition, the market launch of further robotic operating systems from other manufacturers is imminent, and there is a well-founded hope that new impulses will spur further development in the emerging competition. Another big advancement on the horizon is the integration of augmented reality, making it possible for intraoperative navigation through overlapping MRI images.

\section{Conclusions}

Esophagectomy is a very difficult procedure with high rates of morbidity and mortality and huge differences in technique between robotic centers and surgeons, as well as differences in outcome assessments. When first introduced, only small case series or even case reports from the first experiences were available, which showed that RAMIE was safe and feasible. With increasing experience, the first retrospective analyses of prospectively collected data were published. These showed a non inferiority or even a superiority of RAMIE compared to MIE or open esophagectomy for some primary endpoints, such as estimated blood loss, R0 resection, or even mortality and morbidity. The first randomized trial supported these findings. However, the data available are still biased because of the varying stages of the learning curve, currently making it nearly impossible to make a fair comparison. Another step towards better comparability is the standardized documentation of complications. Low et al. [27] and the Esophagectomy Complication Consensus Group proposed a system for defining and recording perioperative complications associated with esophagectomy. This should provide an infras- 
tructure to standardize international data collection and facilitate future comparative studies and qualityimprovement projects. Nevertheless, the available studies suggest benefits regarding length of stay, clinical outcomes, and quality of life-if patients are treated in an experienced center with a standardized RAMIE technique. In addition, technical possibilities combined with robotic surgery allow faster and therefore safer surgical education, reducing patient morbidity and mortality. The rapid development in this field of surgery is certainly not yet complete, as highlighted by the planned market launch of the da Vinci Single Port System. Based on the ongoing technical advances in robotic surgery and the positive results from single center experiences, it will be exciting to see whether the results from ongoing prospective studies can support the proposed noninferiority of robotic esophagectomy, making RAMIE a beneficial tool in the treatment of esophageal cancer.

Funding Open Access funding enabled and organized by Projekt DEAL.

Conflict of interest T. Becker and J.-H. Egberts received grants for training with the da Vinci Xi Surgical System through Intuitive Surgical Sàrl. J.-H. Egberts works as a proctor for Intuitive Surgical Sàrl. T. Becker received the da Vinci ${ }^{\circledR} \mathrm{Xi}$ Surgical System from Intuitive Surgical Sàrl for the purpose of clinical research. J.-N. Kersebaum and T. Möller state that there is no conflict of interest. We declare that we have no further competing interests.

Open Access This article is licensed under a Creative Commons Attribution 4.0 International License, which permits use, sharing, adaptation, distribution and reproduction in any medium or format, as long as you give appropriate credit to the original author(s) and the source, provide a link to the Creative Commons licence, and indicate if changes were made. The images or other third party material in this article are included in the article's Creative Commons licence, unless indicated otherwise in a credit line to the material. If material is not included in the article's Creative Commons licence and your intended use is not permitted by statutory regulation or exceeds the permitted use, you will need to obtain permission directly from the copyright holder. To view a copy of this licence, visit http://creativecommons.org/licenses/by/4.0/.

\section{References}

1. Chan DSY, Reid TD, Howell I, Lewis WG. Systematic review and meta-analysis of the influence of circumferential resection margin involvement on survival in patients with operable oesophageal cancer. Br J Surg. 2013;100(4):456-64.

2. Markar SR, et al. Significance of microscopically incomplete resection margin after esophagectomy for esophageal cancer. Ann Surg. 2016;263(4):712-8.

3. Enzinger PC, Mayer RJ. Esophageal Cancer. N Engl J Med. 2003;349(23):2241-52.

4. Giugliano DN, Berger AC, Rosato EL, Palazzo F. Total minimally invasive esophagectomy for esophageal cancer: approaches and outcomes. Langenbecks Arch Surg. 2016;401(6):747-56.

5. MarietteC, etal. Hybrid minimallyinvasive esophagectomy for esophageal cancer. NEngl J Med. 2019;380(2):152-62.
6. Taurchini M, Cuttitta A. Minimally invasive and robotic esophagectomy: state of the art. JVis Surg. 2017;3:125-125.

7. Kauppila JH, Xie S, Johar A, Markar SR, Lagergren P. Metaanalysis of health-related quality of life after minimally invasive versus open oesophagectomy for oesophageal cancer. Br J Surg. 2017;104(9):1131-40.

8. Glatz T, Marjanovic G, Kulemann B, Sick O, Hopt UT, Hoeppner J. Hybrid minimally invasive esophagectomy vs. open esophagectomy: a matched case analysis in 120 patients. Langenbecks Arch Surg. 2017;402(2):323-31.

9. Melvin WS, et al. Computer-enhanced robotic telesurgery. Initial experience in foregut surgery. Surg Endosc. 2002;16(12):1790-2.

10. Kernstine $\mathrm{KH}$, et al. The robotic, 2-stage, 3-field esophagolymphadenectomy. J Thorac Cardiovasc Surg. 2004;127(6):1847-9.

11. Murthy RA, Clarke NS, Kernstine KH. Minimally invasive and robotic esophagectomy: a review. Innov Technol Tech Cardiothorac Vasc Surg. 2018;13(6):391-403.

12. Kang N, et al. Major complications of minimally invasive Ivor Lewis oesophagectomy using the purse stringstapled anastomotic technique in 215 patients with oesophageal carcinoma. Interact CardioVasc Thorac Surg. 2018;27(5):708-13.

13. Tagkalos E, Goense L, Hoppe-Lotichius M, et al. Robotassisted minimally invasive esophagectomy (RAMIE) compared to conventional minimally invasive esophagectomy (MIE) for esophageal cancer: a propensity-matched analysis. Dis Esophagus. 2020;33(4):doz060. https://doi.org/10. 1093/dote/doz060.

14. Zhang Y, et al. Early outcomes of robot-assisted versus thoracoscopic-assisted Ivor lewis esophagectomy for esophageal cancer: a propensity score-matched study. Ann Surg Oncol. 2019;26(5):1284-91.

15. Grimminger PP, Tagkalos E, Hadzijusufovic E, Corvinus F, Babic B, Lang $\mathrm{H}$. Change from hybrid to fully minimally invasive and robotic esophagectomy is possible without compromises. Thorac Cardiovasc Surg. 2019;67(7):589-96.

16. van der Sluis PC, et al. Robot-assisted minimally invasive thoracolaparoscopic esophagectomy versus open transthoracic esophagectomy for resectable esophageal cancer: a randomized controlled trial. Ann Surg. 2019;269(4):621-30.

17. Biere SS, et al. Traditional invasive vs. minimally invasive esophagectomy: a multi-center, randomized trial (TIMEtrial). BMC Surg. 2011;11(1):2.

18. Yang Y, et al. Robot-assisted esophagectomy (RAE) versus conventional minimally invasive esophagectomy (MIE) for resectable esophageal squamous cell carcinoma: Protocol for a multicenter prospective randomized controlled trial (RAMIE trial, robot-assisted minimally invasive Esophagectomy). BMCCancer. 2019;19(1):608.

19. Egberts J-H, Beham A, Ghadimi M. Aufbau eines Roboterprogramms. Zentralbl Chir Z Allg Visz Thorax Gefäßchir. 2016;141(2):143-4.

20. Zorn KC, et al. Training, credentialing, proctoring and medicolegal risks of robotic urological surgery: recommendations of the Society of Urologic Robotic Surgeons. J Urol. 2009;182(3):1126-32.

21. van Hillegersberg R, Seesing MFJ, Brenkman HJF, Ruurda JP. Roboterassistierte minimal-invasive Ösophagektomie. Chirurg. 2016;87(8):635-42.

22. Egberts JH, Stein H, Aselmann H, Jan-Hendrik A, Becker T. Fully robotic da Vinci Ivor-Lewis esophagectomy in fourarm technique-problems and solutions. Dis Esophagus. 2017;30(12):1-9. 
23. Van WorkumF, etal. Learning curve and associated morbidity of minimally invasive esophagectomy: a retrospective multicenter study. Ann Surg. 2019;269(1):88-94.

24. van der Sluis PC, Ruurda JP, van der Horst S, Goense L, van Hillegersberg R. Learning curve for robot-assisted minimally invasive thoracoscopic esophagectomy: results from 312 cases. Ann Thorac Surg. 2018;106(1):264-71.

25. Plat VD, Stam WT, Schoonmade LJ, Heineman DJ, van der Peet DL, Daams F. Implementation of robot-assisted Ivor Lewis procedure: Robotic hand-sewn, linear or circular technique?. Am J Surg. 2020;220(1):62-68. https://doi.org/ 10.1016/j.amjsurg.2019.11.031.

26. Egberts J-H, Schlemminger M, Hauser C, Beckmann J-H, Becker T. Robot-assisted cervical esophagectomy (RACE procedure) using a single port combined with a transhiatal approach in a rendezvous technique: a case series. Langenbecks Arch Surg. 2019;404(3):353-8.

27. Low DE, et al. International consensus on standardization of data collection for complications associated with esophagectomy: Esophagectomy Complications Consensus Group (ECCG). Ann Surg. 2015;262(2):286-94.

28. Giulianotti PC, et al. Robotics in general surgery: personal experience in a large community hospital. Arch Surg. 2003;138(7):777-84.

29. Horgan S, Vanuno D. Robots in laparoscopic surgery. J Laparoendosc AdvSurg Tech. 2001;11(6):415-9.

30. Bodner JC, et al. Robotic-assisted thoracoscopic surgery (RATS) for benign and malignant esophageal tumors. Ann Thorac Surg. 2005;80(4):1202-6.

31. Ruurda JP, van der Sluis PC, van der Horst S, van Hilllegersberg R. Robot-assisted minimally invasive esophagectomy for esophageal cancer: a systematic review. J Surg Oncol. 2015;112(3):257-65.

32. Dapri G, Himpens J, Cadière G-B. Robot-assisted thoracoscopic esophagectomy with the patient in the prone position. J Laparoendosc Adv Surg Tech A. 2006;16(3):278-85.

33. Espat NJ, Jacobsen G, Horgan S, Donahue P. Minimally invasive treatment of esophageal cancer: laparoscopic staging to robotic esophagectomy. Cancer J Sci Am. 2005;11(1):10-7.

34. Van Hillegersberg R, Boone J, Draaisma WA, Broeders IAMJ, Giezeman MJMM, Rinkes IHMB. First experience with robot-assisted thoracoscopic esophagolymphadenectomy for esophageal cancer. Surg Endosc Other Interv Tech. 2006;20(9):1435-9.

35. Anderson C, et al. Robotic surgery for gastrointestinal malignancies. Int J Med Robot. 2007;3(4):297-300.

36. Kernstine $\mathrm{KH}$. The first series of completely robotic esophagectomies with three-field lymphadenectomy: Initial experience. Surg Endosc Other Interv Tech. 2008;22(9):2102.

37. Braumann C, Jacobi CA, Menenakos C, Ismail M, Rueckert JC, Mueller JM. Robotic-assisted laparoscopic and thoracoscopic surgery with the da Vinci system: a 4-year experience in a single institution. Surg Laparosc Endosc Percutan Tech. 2008;18(3):260-6.

38. Galvani CA, et al. Robotically assisted laparoscopic transhiatal esophagectomy. Surg Endosc. 2008;22(1):188-95.

39. Boone J, Schipper MEI, Moojen WA, Borel Rinkes IHM, Cromheecke GJE, van Hillegersberg R. Robot-assisted thoracoscopic oesophagectomy for cancer. Br J Surg. 2009;96(8):878-86.

40. Kim DJ, Hyung WJ, Lee CY, et al. Thoracoscopic esophagectomy for esophageal cancer: feasibility and safety of robotic assistance in the prone position. J Thorac Cardiovasc Surg. 2010;139(1):53-59.el. https://doi.org/10.1016/j. jtcvs.2009.05.030.
41. Puntambekar SP, Rayate N, Joshi S, Agarwal G. Robotic transthoracic esophagectomy in the prone position: experience with 32 patients with esophageal cancer. J Thorac Cardiovasc Surg. 2011;142(5):1283-4.

42. Dunn KB, Scarpinata R, Aly EH. Does robotic rectal cancer surgery offer improved early postoperative outcomes? Dis Colon Rectum. 2013;56(2):253-62.

43. Suda K, et al. Robot-assisted thoracoscopic lymphadenectomy along the left recurrent laryngeal nerve for esophageal squamous cell carcinoma in the prone position: technical report and short-term outcomes. World J Surg. 2012;36(7):1608-16.

44. Cerfolio RJ, Wei B, Hawn MT, Minnich DJ. Robotic esophagectomy for cancer: early results and lessons learned. Semin Thorac Cardiovasc Surg. 2016;28(1): 160-9.

45. de la Fuente SG, Weber J, Hoffe SE, Shridhar R, Karl R, Meredith KL. Initial experience from a large referral center with robotic-assisted Ivor Lewis esophagogastrectomy for oncologic purposes. Surg Endosc. 2013;27(9):3339-47.

46. Diez Del Val I, et al. Contribution of robotics to minimally invasive esophagectomy. J RobotSurg. 2013;7(4):325-32.

47. Hernandez JM, et al. Defining the learning curve for robotic-assisted esophagogastrectomy. J Gastrointest Surg. 2013;17(8):1346-51.

48. Ishikawa $\mathrm{N}$, Kawaguchi $\mathrm{M}$, Inaki N, Moriyama $\mathrm{H}$, Shimada M, WatanabeG. Robot-assisted thoracoscopichybrid esophagectomy in the semi-prone position under pneumothorax. Artif Organs. 2013;37(6):576-80.

49. Mori K, Yamagata Y, Wada I, Shimizu N, Nomura S, Seto Y. Robotic-assisted totally transhiatal lymphadenectomy in the middle mediastinum for esophageal cancer. J Robot Surg. 2013;7(4):385-7.

50. Weksler B, Sharma P, Moudgill N, Chojnacki KA, Rosato EL. Robot-assisted minimally invasive esophagectomy is equivalent to thoracoscopicminimallyinvasive esophagectomy. Dis Esophagus. 2012;25(5):403-9.

51. Sarkaria IS, et al. Intraoperative near-infrared fluorescence imaging as an adjunct to robotic-assisted minimally invasive esophagectomy. Innovations. 2014;9(5):391-3.

52. Coker AM, et al. Outcomes of robotic-assisted transhiatal esophagectomy for esophageal cancer after neoadjuvant chemoradiation. J Laparoendosc Adv Surg Tech. 2014;24(2):89-94.

53. Sarkaria IS, et al. Combined thoracoscopic and laparoscopic robotic-assisted minimally invasive esophagectomy using a four-arm platform: experience, technique and cautions during early procedure development. Eur J Cardiothorac Surg. 2013;43(5):e107-e15.

54. Trugeda S, Fernández-Díaz MJ, Rodríguez-Sanjuán JC, Palazuelos CM, Fernández-Escalante C, Gómez-Fleitas M. Initial results of robot-assisted Ivor-Lewis oesophagectomy with intrathoracic hand-sewn anastomosis in the prone position. Int J Med Robot. 2014;10(4):397-403.

55. Puntambekar S, et al. Robotic transthoracic esophagectomy. BMCSurg. 2015;15(1):47.

56. Meredith K, Blinn P, Maramara T, Takahashi C, Huston J, Shridhar R. Comparative outcomes of minimally invasive and robotic-assisted esophagectomy. Surg Endosc. 2020;34(2):814-20.

57. Harbison GJ, Vossler JD, Yim NH, Murayama KM. Outcomes of robotic versus non-robotic minimally-invasive esophagectomy for esophageal cancer: an American College of Surgeons NSQIP database analysis. Am J Surg. 2019;218(6):1223-8.

58. Yang Y,ZhangX, LiB, etal. Short- and mid-term outcomes of robotic versus thoraco-laparoscopic McKeown esophagec- 
tomy for squamous cell esophageal cancer: a propensity score-matched study. Dis Esophagus. 2020;33(6):doz080. https://doi.org/10.1093/dote/doz080.

59. Chen J, etal. Comparisons of short-term outcomes between robot-assisted and thoraco-laparoscopic esophagectomy with extended two-field lymph node dissection for re- sectable thoracic esophageal squamous cell carcinoma. JThorac Dis. 2019;11(9):3874-80.

Publisher's Note Springer Nature remains neutral with regard to jurisdictional claims in published maps and institutional affiliations. 